\section{Asymptomatic Epstein-Barr virus shedding in the urine of kidney transplant recipients: case reports and review of the literature}

\author{
Maryam Rahbar, ${ }^{1}$ \\ Gholamreza Poormand, 2 \\ Masoud Karkhaneh Mahmoodi, ${ }^{3}$ \\ Aboozar Jazayeri, ${ }^{1}$ \\ Seyed Mohammad Jazayeri ${ }^{3}$ \\ 'Department of Nephrology and \\ 2Department of Urology, Sina Hospital, \\ Tehran University of Medical Sciences; \\ ${ }^{3}$ Hepatitis B Molecular Laboratory, \\ Department of Virology, School of Public \\ Health, Tehran University of Medical \\ Sciences, Tehran, Iran
}

\section{Abstract}

Epstein-Barr virus (EBV) is associated with a wide range of malignancies and complications like post-transplant lymphoproliferative disorder (PTLD). To suppress active EBV infection in transplant recipients, who are at a heightened risk of developing PTLD, EBV DNAemia monitoring has been recommended. Quantitative multiplex real time polymerase chain reaction (QMRTPCR) offered the advantage of detection of more than one target in the same sample. We present four cases of kidney transplant recipient who were admitted for rising serum creatinine between 9 and 20 months post-transplant with a suspicion of BKV-associated nephropathy. All but one patient had unusual sonography findings in their genitourinary tracts and were positive for urinary culture for bacteria. Using a commercial QMRTPCR that could detect and quantitate $\mathrm{BKV}, \mathrm{EBV}$ and cytomegalovirus simultaneously, all patients were positive for EBV in their urine for the levels between 2500 and $8 \times 10^{8} \mathrm{U} / \mathrm{mL}$. None of the patients had any symptoms regarding this finding. On following up survey 3 month post discharge from hospital, all patients were negative for plasma and urine EBV. Absent of EBV DNAemia together with alternating phases of detectable EBV in urine might reflect the presence of functionally efficient central/effector memory $\mathrm{T}$ cells against EBV. The significance of this finding in immunocompromized patients necessitates prospective longitudinal studies.

\section{Introduction}

Epstein-Barr virus (EBV), a member of gamma herpes virus, infects most adults worldwide and persists throughout the lifetime of its host. The possibility of viral reactivation is a frequent concern for recipients of organ transplantation, especially its association with post-transplant lymphoproliferative disorder (PTLD) Solid organ transplantation (SOT) or hematopoietic stem cell transplantation (HSCT) recipients with EBV-positive early PTLD have significantly higher viral load measured in blood than PTLD negative patients; high viral load levels often precede the clinical presentation of PTLD. ${ }^{1-3}$ Routine EBV viral load can provide an early diagnosis of PTLD and support pre-emptive schema. ${ }^{4}$ On the other hand, a proportion of patients with high EBV viral loads may not exhibit PTLD or a proportion of patients with low EBV viral loads may have PTLD. ${ }^{5}$ So far, no report has been published regarding the temporary detection of EBV in urine of renal graft recipient. Measuring the EBV load is essential to follow and diagnose EBV-associated diseases and to explore the pathogenesis of EBV infection. EBV DNA can sometimes be detected in immunocompetent individuals and often in immunosuppressed patients without symptoms or clinical sequelae. Interpretation of VL results is often difficult, particularly in immunosuppressed patients. Viral reactivation can occur in seropositive subjects. This does not cause symptoms in the immunocompetent patient but serious disease can occur in immunosuppressed hosts. Trigger points for intervention are poorly defined as natural history studies of PTLD in high risk patients where clinicians are blinded because the implemented interventions have been limited. Moreover, adult PTLD patients have been observed to relapse in presence of persistently low VL. Here, we report 4 cases of cadaver kidney transplantation patients who referred to our hospital post transplantation because of rising in their serum creatinine. We present unusual cases of urinary EBV shedding that were suspected to have BK virus or CMV infections. More case studies are needed to explore the clinical significance of such finding in renal transplant recipients.

\section{Materials and Methods}

Viral nucleic acids from plasma and urine specimens were extracted using an automated extractor, Magnapure 96 (Roche, Basel, Switzerland), according to manufacturer's recommendation. Internal control was added to each specimen before loading the trays. The use of an internal control of each reaction tube excluded false negatives due to nonspecific inhibitors of the PCR enzymes. Quantitative Multiplex Real Time PCR (QMRTPCR) was carried out on $5 \mu \mathrm{L}$ of extracted materials using
Correspondence: Seyed Mohammad Jazayeri, Hepatitis B Molecular Laboratory, Department of Virology, School of Public Health, Tehran University of Medical Sciences, P0 Box: 151556446, Tehran, Iran.

Tel/Fax: +98.21.8899.2660.

E-mail: jazayerism@tums.ac.ir

Key words: Post-transplant lymphoproliferative disorder, Epstein-Barr virus, BKV associated nephropathy.

Contributions: the authors contributed equally.

Conflict of interest: the authors declare no potential conflict of interest.

Funding: this study was supported by Research Center for Urology, Sina Hospital.

Received for publication: 3 August 2016. Revision received: 30 August 2016.

Accepted for publication: 10 October 2016

This work is licensed under a Creative Commons Attribution-NonCommercial 4.0 International License (CC BY-NC 4.0).

(C) Copyright M. Rahbar et al., 2016

Licensee PAGEPress, Italy

Infectious Disease Reports 2016; 8:6817

doi:10.4081/idr.2016.6817

BCE kit (for the detection of BK virus, CMV and EBV, respectively) (Fast-track diagnostics, Luxembourg), according to manufacturer's instructions. Each real time reaction incorporated at least three standards for analysis of quantification curves in each sample per run. If a positive laboratory test result was not compatible with the clinical picture of the patients, the assay was repeated by another technician on the same sample.

\section{Case Report \#1}

A 44 years old woman who underwent kidney transplantation for diabetes and hypertension in post-transplant month (PTM) 14 was admitted for the suspicion of recurrent urinary tract infections (UTI) since her transplantation. Her immunosuppression consisted of cyclosporine (100 mg b.i.d.), mycophenolate mofetil (1000 mg b.i.d.) and prednisone (5 mg daily). On routine follow-up, she had elevated serum creatinine $(2.2 \mathrm{mg} / \mathrm{dL})$. Ultrasound showed hydronephrosis of her allograft with urine collections. All other blood tests were in the normal ranges. The blood culture was positive for $E$. coli; hence she received imipenem $500 \mathrm{mg}$ b.i.d. for 10 days. In QMRTPCR, EBV was positive in both plasma $\left(3.5 \times 10^{3} \mathrm{U} / \mathrm{mL}\right)$ and urine $\left(4.2 \times 10^{3} \mathrm{U} / \mathrm{mL}\right)$ (Table 1). Also CMV 
was positive in plasma $\left(1.8 \times 10^{3} \mathrm{U} / \mathrm{mL}\right)$. BKV was negative (Table 1). She was subsequently discharged with normal creatinine. Her follow up urine and plasma PCR analysis 3-months was positive only for CMV $5 \times 10^{3} \mathrm{U} / \mathrm{mL}$ in urine.

\section{Case Report \#2}

A 47 years old woman with the known history of hypertension for $>15$ years, was admitted in post-transplant month 10 due to high creatinine. Her immunosuppression consisted of cyclosporine (75 mg b.i.d.), mycophenolate mofetil (500 mg b.i.d.) and prednisone (10 mg daily). Ultrasound and pelvic computerized tomography (CT) scan showed hydronephrosis and urine collections with septation. In QMRTPCR, CMV was positive in both plasma $\left(3.9 \times 10^{2} \mathrm{U} / \mathrm{mL}\right)$ and urine $\left(4 \times 10^{3} \mathrm{U} / \mathrm{mL}\right)$ (Table 1). EBV was positive only in urine $\left(3.2 \times 10^{3} \mathrm{U} / \mathrm{mL}\right)$ (Table 1$)$. However, BK virus was absent in both compartments. Upon urinary culture, E. coli was found; therefore, she received ceftriaxone $1 \mathrm{~g}$ b.i.d. for 10 days for her UTI. Her serum creatinine upon discharge was $1.2 \mathrm{mg} / \mathrm{dL}$. Her follow up testing showed no $\mathrm{EBV}, \mathrm{CMV}$ and BKV in her plasma and urine.

\section{Case Report \#3}

A 54 years old woman with a known long history of diabetes and hypertension was admitted due to low back pain. A serum creatinine of $1.8 \mathrm{mg} / \mathrm{dL}$ was found in routine testing posttransplantation. Her immunosuppression consisting of cyclosporine (75 mg b.i.d.), mycophenolate mofetil (500 mg TDS) and prednisone (7.5 mg daily). In ultrasonography, the urinary and bladder systems were reported to be normal. However, an ovarian tumor with a size of $27 \mathrm{~mm}$ was reported by ultrasonography. She had no UTI. On day 10, her body temperature increased to $38^{\circ} \mathrm{C}$. In QMRTPCR, CMV was detected in plasma as high as $7 \times 10^{3}$ copy/mL. She received ganciclovir IV $120 \mathrm{mg}$ b.i.d until CMV levels dropped to undetectable levels. Urine EBV was $8 \times 10^{8} \mathrm{U} / \mathrm{mL}$ level (Table 1). Afterwards, she underwent ovarian surgery for her benign tumor successfully. She was discharged with normal range of serum creatinine seven days after discontinuation of ganciclovir. Her follow up testing showed no EBV, $\mathrm{CMV}$ and BKV in her plasma and urine.

\section{Case Report \#4}

A 52 years old man was admitted at post transplant month 20 for fever. His immunosuppression consisting of tacrolimus (1 mg b.i.d.), mycophenolate mofetil (500 mg b.i.d.) and prednisone (10 mg daily). 14 months following the transplantation, he had presented with repeated urinary tract infections and elevated serum creatinine concentrations. Imagining studies showed reflux grade IV. Upon urinary and blood culture testing, Klebsiella were positive. Therefore, meropenem $500 \mathrm{mg}$ b.i.d. was added to his immunosuppressive regimen. His urine output dropped suddenly with a rise in creatinine, requiring hemodialysis three times weekly for two weeks. In QMRTPCR, CMV and EBV were positive in urine: $3 \times 10^{5} \mathrm{U} / \mathrm{mL}$ and $2.5 \times 10^{3} \mathrm{U} / \mathrm{mL}$, respectively. Plasma was negative for both pathogens. Ultimately, she was discharged with negative blood and urine cultures and normal serum creatinine. His urine was positive only for CMV $\left(7 \times 10^{6}\right)$.

\section{Discussion}

The present study includes four cases of cadaver kidney transplant recipients admitted to our center 9 to 20 PTM because of rise in their serum creatinine concentrations in three cases. All patients had end-stage renal disease (ERSD) and all had a history of 1-2 years dialysis before their renal transplantation. To the best of our knowledge, this is the first report of asymptomatic EBV shedding in the urine of kidney transplant recipients. All the patients were under different regimen of immunosuppressive drugs. Also, they all were received CMV antivirals for the first 3 months posttransplantation, including ganciclovir 1.25 $\mathrm{mg} / \mathrm{kg}$ IV daily as induction for one month, which then switched to oral valganciclovir (according to their serum creatinine levels, b.i.d). In CMV DNAemia cases, the level of viral load was below the cut off levels for anti-CMV treatment in our center $(2000 \mathrm{U} / \mathrm{mL})$. All patients were negative for EBV IgM and were positive for EBV IgG serology. For all cases, quantitative multiplex real time PCR for BKV, $\mathrm{CMV}$ and $\mathrm{EBV}$ in the urine and serum were carried out for the initial suspicion of BKVN. Upon finding unusual test results, the assays were repeated. One advantage of this PCR method was its ability to identify the presence of two of herpes viruses plus BKV within the same sample at the same time. We found that all 4 patients had different levels of EBV in their urine, despite having no symptoms regarding the involvement of kidney or a systemic involvement like chronic HBV infection. After primary EBV infection, virus can be isolated from saliva or peripheral blood. However, to the best of our knowledge, this is the first report of asymptomatic urinary EBV shedding

Table 1. Demographic, clinical and virological details of cases.

\begin{tabular}{|c|c|c|c|c|}
\hline Characteristics & Case 1 & Case 2 & Case 3 & Case 4 \\
\hline Age & 44 & 47 & 54 & 52 \\
\hline Gender & $\mathrm{F}$ & $\mathrm{F}$ & $\mathrm{F}$ & M \\
\hline Reasons for Tx & Diabetes/Hypertension & Hypertension & Diabetes/Hypertension & Unknown \\
\hline Post-transplant month* & 14 & 10 & 9 & 20 \\
\hline Immunosuppressive regimen & $\begin{array}{l}\text { Cyclosporine; } \\
\text { Mycophenolate mofetil; } \\
\text { Prednisolone }\end{array}$ & $\begin{array}{l}\text { Cyclosporine; } \\
\text { Mycophenolate mofetil; } \\
\text { Prednisolone }\end{array}$ & $\begin{array}{l}\text { Cyclosporine; } \\
\text { Mycophenolate mofetil; } \\
\text { Prednisolone }\end{array}$ & $\begin{array}{l}\text { Tacrolimus; } \\
\text { Mycophenolate mofetil; } \\
\text { Prednisolone }\end{array}$ \\
\hline Creatinine* $^{*}$ & 1.8 & 1.4 & 1.5 & 5.6 \\
\hline CMV Plasma/Urine & CMV $1.8 \times 10^{3} / \mathrm{Neg}$ & $3.9 \times 10^{2} / 4 \times 10^{3}$ & $7 \times 10^{3} / \mathrm{Neg}$ & $\mathrm{Neg} / 3 \times 10^{5}$ \\
\hline BKV Plasma/Urine & $\mathrm{Neg} / \mathrm{Neg}$ & Neg/Neg & Neg/Neg & Neg/Neg \\
\hline EBV Plasma/Urine & $3.5 \times 10^{3} / 4.2 \times 10^{3}$ & $\mathrm{Neg} / 3.2 \times 10^{3}$ & $\mathrm{Neg} / 8 \times 10^{8}$ & $\mathrm{Neg} / 2.5 \times 10^{3}$ \\
\hline Diagnosis & Hydronephrosis-UTI & Hydronephrosis-UTI & CMV infection & UTI \\
\hline Follow Up CMV Plasma/Urine & $\mathrm{Neg} / 5 \times 10^{3}$ & $\mathrm{Neg} / \mathrm{Neg}$ & Neg/Neg & $\mathrm{Neg} / 7 \times 10^{6}$ \\
\hline Follow Up BKV Plasma/Urine & Neg/Neg & $\mathrm{Neg} / \mathrm{Neg}$ & $\mathrm{Neg} / \mathrm{Neg}$ & $\mathrm{Neg} / \mathrm{Neg}$ \\
\hline Follow Up EBV Plasma/Urine & $\mathrm{Neg} / \mathrm{Neg}$ & $\mathrm{Neg} / \mathrm{Neg}$ & Neg/Neg & $\mathrm{Neg} / \mathrm{Neg}$ \\
\hline
\end{tabular}

All viral loads are reported as international unit per milliliter. F, female; M, male; Neg, Negative. *at the time of admission. 
in immunodeficient individuals.

The European Best Practice Guidelines for Renal Transplantation and Kidney Disease: Improving Global Outcomes Transplant Work Group and other centers recommend testing for EBV nucleic acid in high-risk renal transplant patients every occasion soon after transplantation until a distinct period. ${ }^{6,7}$ In healthy transplant recipients, baseline viral loads tend to be higher than in normal immunocompetent hosts, both in whole blood and in plasma, and viral loads over time reflect the progression and resolution of PTLD. ${ }^{8}$

Detection of EBV in both healthy male and female genital secretions has been reported., ${ }^{9,10}$ However, the level of EBV in genital secretions was lower than in saliva. ${ }^{11}$ Also, detection of EBV DNA in plasma is an uncommon phenomena in healthy individuals. ${ }^{12}$ EBV has also been detected from spleen, intestines, pancreas and urinary bladder in autopsies specimen..$^{13}$ It is not clear if $B$ cells resided in kidneys could be infected by EBV and support virus replication. Also, it is uncertain how this shedding is maintained, but the latent EBV load in urine might reflect a balance between removal of EBV infected cells due to the half-life of memory B cells and reinfection of new memory $B$ cells during virus reactivation. Nevertheless, in vitro evidence for direct infection and replication of EBV in cultured normal human epithelial cells has been reported previously. ${ }^{14}$ More investigations will unravel the exact mechanism of EBV shedding in urine and its relation to immunosuppression after kidney transplantation and perhaps occurrence of PTLD. All but one patient admitted to the hospital for UTI. It might be that EBV could predispose the kidney to the secondary bacterial infections. All patients had another testing on their urine and plasma 3 months post discharge. All were negative for EBV.

\section{Conclusions}

One of interesting finding in the present study was the presence of CMV DNAemia in 3 patients (cases1, 2 and 3 ) and CMV viruria in 2 patients (cases 2 and 4) despite not being clinically significant. While asymptomatic shedding of CMV in the urine is not unusual in healthy (immunocompetent) subjects, coinfec- tion of EBV with CMV or other viruses might be a risk factor for developing PTLD. ${ }^{8}$ We appreciate that these patients did not present any symptoms that could be assigned as being co infected with both EBV and CMV in different body compartment. Therefore, we believe more frequent testing is worth considering if these patients show any sign or symptoms regarding PTLD due to coinfection. Two of patients were positive for CMV in their urine 3 months after their discharge; however, they were symptomfree. Taken together, we believe that in transplant recipients, asymptomatic shedding of EBV finding in body fluids including urine in the absence of evidence for invasive disease (virus found in tissues or in blood) should be viewed with suspension as this hypothesis has been also raised by others generally for herpes viruses. ${ }^{15}$

In conclusion, we presented asymptomatic presence of EBV in the urine of kidney transplant recipients around the first post-transplantation year who admitted for UTI and for the suspension of BKVN. Prospective studies are required to answer many questions regarding the significance of this unusual finding in immunocompromized patients.

\section{References}

1. Rowe DT, Qu L, Reyes J, et al. Use of quantitative competitive PCR to measure Epstein-Barr virus genome load in the peripheral blood of pediatric transplant patients with lymphoproliferative disorders. J Clin Microbiol 1997;35:1612-5.

2. Wagner HJ, Wessel M, Jabs W, et al. Patients at risk for development of posttransplant lymphoproliferative disorder: plasma versus peripheral blood mononuclear cells as material for quantification of Epstein-Barr viral load by using real-time quantitative polymerase chain reaction. Transplantation 2001;72:1012-9.

3. Lee TC, Savoldo B, Rooney CM, et al. Quantitative EBV viral loads and immunosuppression alterations can decrease PTLD incidence in pediatric liver transplant recipients. Am J Transplant 2005;5: 2222-8.

4. Gartner B, Preiksaitis JK. EBV viral load detection in clinical virology. $\mathrm{J}$ Clin Virol 2010;48:82-90.
5. Cho YU, Chi HS, Jang S, et al. Pattern analysis of Epstein-Barr virus DNAemia and its significance in the evaluation of organ transplant patients suspected of having posttransplant lymphoproliferative disorders. Am J Clin Pathol 2014;141:26874.

6. EBPG Expert Group on Renal Transplantation. European best practice guidelines for renal transplantation. Section IV: Long-term management of the transplant recipient. IV.6.1. Cancer risk after renal transplantation. Post-transplant lymphoproliferative disease (PTLD): prevention and treatment. Nephrol Dial Transplant 2002;17:31-6.

7. KDIGO. KDIGO clinical practice guideline for the care of kidney transplant recipients. Am J Transplant 2009;9:S1-155.

8. Gulley ML, Tang W. Using Epstein-Barr viral load assays to diagnose, monitor, and prevent posttransplant lymphoproliferative disorder. Clin Microbiol Rev 2010;23:35066.

9. Enbom M, Strand A, Falk KI, Linde A. Detection of Epstein-Barr virus, but not human herpesvirus 8, DNA in cervical secretions from Swedish women by realtime polymerase chain reaction. Sex Transm Dis 2001;28:300-6.

10. Israele V, Shirley P, Sixbey JW. Excretion of the Epstein-Barr virus from the genital tract of men. J Infect Dis 1991;163:1341-3.

11. Thomas R, Macsween KF, McAulay K, et al. Evidence of shared Epstein-Barr viral isolates between sexual partners, and low level EBV in genital secretions. J Med Virol 2006;78:1204-9.

12. Kimura H, Ito Y, Suzuki R, Nishiyama Y, et al. Measuring Epstein-Barr virus (EBV) load: the significance and application for each EBV-associated disease. Rev Med Virol 2008;18:305-19.

13. Chen T, Hudnall SD. Anatomical mapping of human herpesvirus reservoirs of infection. Mod Pathol 2006;19:726-37.

14. Sixbey JW, Vesterinen EH, Nedrud JG, et al. Replication of Epstein-Barr virus in human epithelial cells infected in vitro. Nature 1983;306:480-3.

15. Fishman JA. Overview: cytomegalovirus and the herpesviruses in transplantation. Am J Transplant 2013;13:1-8. 